\title{
Canistropsis e Nidularium (Bromeliaceae: Bromelioideae) no Parque Nacional da Serra dos Órgãos, Rio de Janeiro, Brasil
}

\author{
Canistropsis and Nidularium (Bromeliaceae: Bromelioideae) in \\ Serra dos Órgãos National Park, Rio de Janeiro, Brazil
}

\author{
Igor Musauer Kessous ${ }^{1}$ \& Andrea Ferreira da Costa ${ }^{2,3}$
}

\begin{abstract}
Resumo
O Parque Nacional da Serra dos Órgãos (PARNASO) está localizado entre os municípios fluminenses de Teresópolis, Petrópolis, Guapimirim e Magé abrangendo ambientes desde Floresta Pluvial Baixo Montana até Campos de Altitude. A família Bromeliaceae possui cerca de 3.503 espécies distribuídas em 59 gêneros. Os gêneros Canistropsis e Nidularium são endêmicos do Brasil e possuem seu centro de diversidade na Mata Atlântica. O objetivo deste trabalho foi inventariar e descrever os táxons presentes no PARNASO, além de propor chaves de identificação dos gêneros e das espécies e fornecer informações sobre a distribuição geográfica e caracterizar sua ocorrência na área do parque. O levantamento bibliográfico e de exsicatas foi feito através das principais monografias da família e pela visita aos principais herbários do Rio de Janeiro. $\mathrm{O}$ trabalho de campo consistiu em expedições para coleta de exemplares no parque. As descrições e a análise dos dados foram feitas com auxílio de literatura especializada. Foram inventariados oito táxons no parque, um de Canistropsis e sete de Nidularium. O presente trabalho contribui com a taxonomia dos gêneros e conservação das espécies no Parque Nacional da Serra dos Órgãos.
\end{abstract}

Palavras-chave: biodiversidade, conservação, florística, Mata Atlântica, taxonomia.

\begin{abstract}
Parque Nacional da Serra dos Órgãos is located between the cities of Teresópolis, Petrópolis, Guapimirim and Magé including from Low Montane Rainforest to High Altitude Fields. Bromeliaceae has about 3.503 species distributed in 59 genera. Canistropsis and Nidularium are endemic of Brazil and have their diversity center in the Atlantic Forest Domain. The goal of this study was to inventory and describe the taxa present in the park, fournishing informations and identification keys to genera and species, as long as information about the geographic distribution and occurrence along the park area. The bibliographic search was done through the principal family monographs, and by visiting the main Rio de Janeiro herbaria. The field work consisted of collecting expeditions in the National Park. The descriptions and analysis were done following current literature and online data. Eight taxa were inventoried, being one of Canistropsis and seven of Nidularium. This study contributes to the genera taxonomy and conservation of the species in the Parque Nacional da Serra dos Órgãos.
\end{abstract}

Key words: biodiversity, conservation, floristics, Atlantic Forest, taxonomy.

\section{Introdução}

A Mata Atlântica é a segunda maior floresta tropical pluvial do continente americano e no passado cobria mais de 1,5 milhões de $\mathrm{km}^{2}$, com 92\% desta área no Brasil (Fundação SOS Mata Atlântica \& INPE 2001; Galindo-Leal \& Câmara 2003). Mesmo com grande parte devastada, ainda abriga cerca de 8.000 espécies endêmicas de plantas vasculares ou 2,7\% das espécies existentes no mundo. Estima-se que a floresta reduziu 1.135.679 de $\mathrm{km}^{2}$ (Myers et al. 2000) nesses últimos anos sendo reduzida a cerca de $11,7 \%$ da sua área original (Ribeiro et al. 2009).

\footnotetext{
'Universidade Federal do Rio de Janeiro, Prog. Pós-graduação em Ciências Biológicas (Botânica), Quinta da Boa Vista, Horto Botânico, 20940-040, Rio de Janeiro, RJ, Brasil.

${ }^{2}$ Universidade Federal do Rio de Janeiro, Depto. Botânica, Museu Nacional, Quinta da Boa Vista, Horto Botânico, 20940-040, Rio de Janeiro, RJ, Brasil.

${ }^{3}$ Autor para correspondência: afcosta@acd.ufrj.br
} 
O estado do Rio de Janeiro encontra-se inteiramente incluído no Domínio Atlântico e apresenta importantes remanescentes da porção setentrional do Corredor da Serra do Mar (Ayres et al. 2005). A região da Serra dos Órgãos é um importante fragmento de Mata Atlântica na região serrana fluminense que fascinou aqueles que chegaram ao Rio de Janeiro no início da colonização do Brasil pelas impressionantes formas do relevo e pala exuberância das suas florestas.

A família Bromeliaceae apresenta no Domínio Atlântico expressiva riqueza e diversidade tanto genérica quanto específica, caracterizando esta região como um dos seus principais centros de diversidade (Martinelli et al. 2008). Possui cerca de 3.503 espécies e 59 gêneros (Gouda et al. continuamente atualizado) sendo destas, 1.172 endêmicas do Brasil (BFG 2015). Entre as oito subfamílias reconhecidas atualmente (Givnish et al. 2007, 2011), Bromelioideae é aquela com maiores problemas de delimitação genérica e cujos conceitos taxonômicos são claramente divergentes entre os diferentes tratamentos (e.g., Baker 1889; Mez 1896, 1934-5; Smith \& Downs 1979). A maioria das hipóteses filogenéticas propostas até o presente converge para o monofiletismo da subfamília e para o reconhecimento de um clado eu-bromelioide com a maioria dos gêneros (e.g., Schulte et al. 2009; Sass \& Specht 2010; Givnish et al. 2011; Silvestro et al. 2014; Evans et al. 2015). O clado nidularióide, tem sido reconhecido em diferentes análises, porém ainda subamostrado e com relacionamentos inconclusivos (Schulte et al. 2009; Evans et al. 2015). O complexo engloba os gêneros Neoregelia, Canistrum, Nidularium, Canistropsis, Wittrockia, Edmundoa, Eduandrea e algumas espécies de Aechmea com inflorescência nidular. Análises filogenéticas baseadas em marcadores moleculares apontam Nidularium e Edmundoa como monofiléticos, no entanto, o posicionamento quanto a Neoregelia, Canistrum e Wittrockia permanece incerto (Brown \& Leme 2000; Horres et al. 2007; Evans et al. 2015). Estudos recentes baseados em três marcadores plastidiais apontam um clado (com baixo suporte) denominado por "Bilbergia-nidularioid complex", devido ao fato das espécies de Billbergia se agruparem junto aos nidularióides (Evans et al. 2015).

Canistropsis (Mez) Leme foi descrito como um subgênero de Nidularium (Mez 1891) e assim tratado por Mez (1896), Smith (1955), Smith \& Downs (1979) e Pereira \& Leme (1986), ou como subgênero de Aregelia (=Neoregelia) (Mez 1934-5).
Leme (1998) estabeleceu o gênero Canistropsis enfatizando o tipo de roseta, em geral estreita e de pequeno porte, e as pétalas agudas ou acuminadas e suberetas a patentes na antese, além de caracteres da anatomia foliar, entre outras características, que claramente o distinguem de Nidularium e Neoregelia. Por sua vez, o gênero Nidularium se caracteriza pelas brácteas involucrais e primárias bem desenvolvidas e acumuladoras de grande quantidade de água e pelas pétalas eretas com ápice cuculado, entre outras (Leme 2000).

Os gêneros Canistropsis (11 spp.) e Nidularium (54 spp.) são endêmicos do Domínio Atlântico (Leme 1998; Leme 2000; Martinelli et al. 2008; Gouda et al. continuamente atualizado). Leme (1998) considerou Canistropsis selloana (Baker) Leme como o representante do gênero ocorrente em matas de galeria nos Campos Rupestres de Minas Gerais, no Domínio dos Cerrados, no entanto, tal espécie foi transferida para o gênero Eduandrea (Leme et al. 2008). A Região Sudeste, especialmente as florestas de encosta das Serras do Mar e da Mantiqueira, e as serras capixabas são o centro de diversidade e endemismo de ambos os gêneros (Martinelli et al. 2008).

O objetivo deste trabalho foi inventariar e descrever os táxons de Canistropsis e Nidularium presentes no PARNASO, além de propor uma chave para identificação dos táxons e comentários sobre sua distribuição na área de estudo. O presente trabalho é parte do Projeto Bromeliaceae organensis o qual visa ampliar o conhecimento da família neste importante fragmento de Mata Atlântica e fornecer subsídios para a conservação e manejo da unidade de conservação.

\section{Material e Métodos}

Área de estudo

O Parque Nacional da Serra dos Órgãos (PARNASO) foi criado em 30 de novembro de 1939 para proteger, além de sua beleza cênica, sua flora e sua fauna, sendo o terceiro parque mais antigo do país. Localizado entre os municípios fluminenses de Guapimirim, Magé, Petrópolis e Teresópolis (Fig. 1 ), entre as coordenadas $22^{\circ} 52^{\prime}$ e $22^{\circ} 54^{\prime}$ 'Sul e $42^{\circ}$ ' e 456' Oeste, a área do parque é de 10.653 hectares com $71 \mathrm{~km}$ de perímetro (Cronenberger \& Viveirosde-Castro 2007).

A vegetação predominante encontrada no PARNASO é a Floresta Tropical Pluvial Atlântica (Rizzini 1979) ou Floresta Ombrófila Densa (Veloso et al. 1991). Em pelo menos cerca de 4.600 hectares, ainda se pode encontrar florestas em estado 

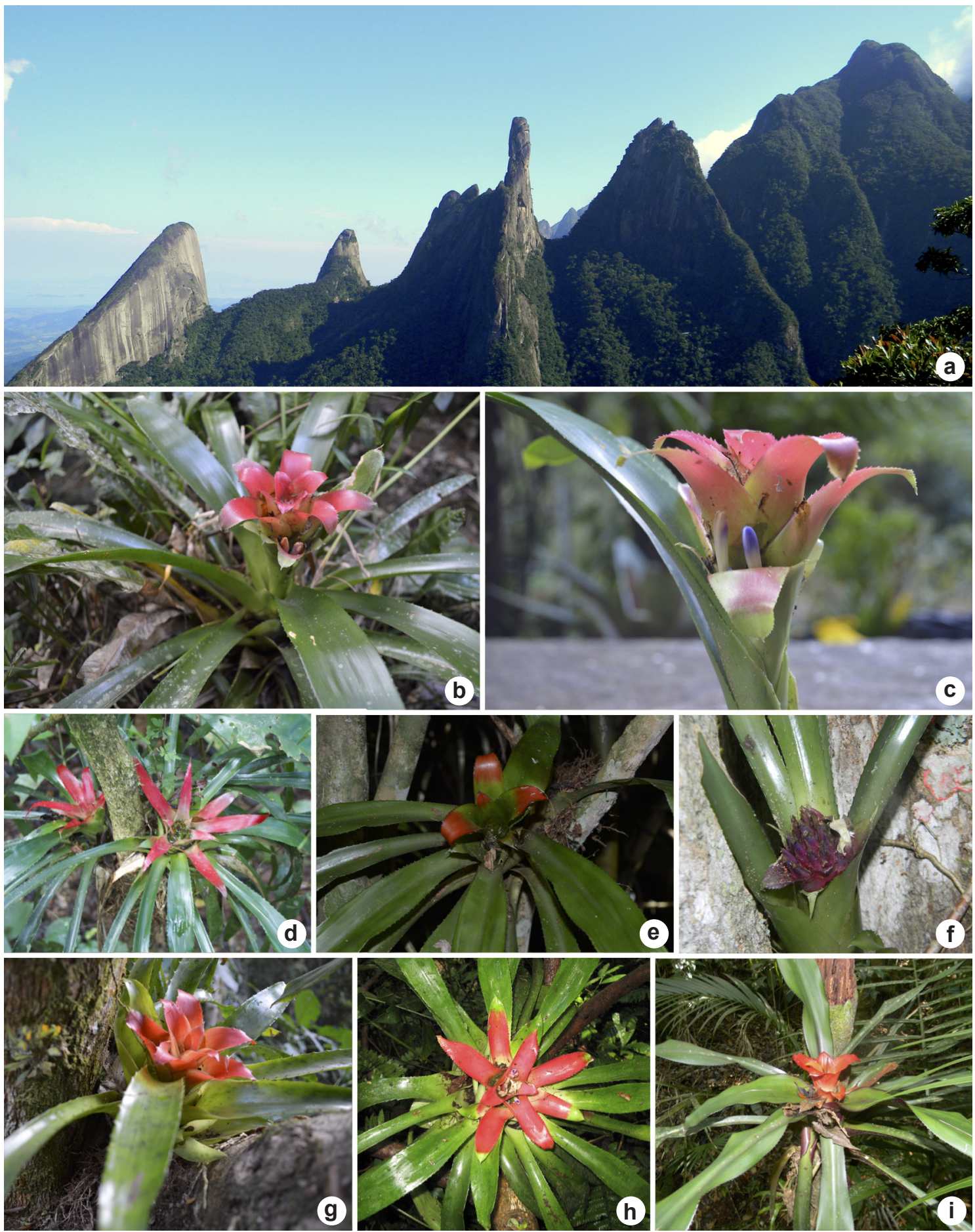

Figura 1 - a. vista das montanhas e matas da região Serra dos Órgãos em Teresópolis; b-c. Nidularium antoineanum; d. N. scheremetiewii; e. N. longiflorum; f. Canistropsis microps; g. N. fulgens; h. N. ferdinando-coburgii; i. N. innocentii. Fotos: Igor Kessous e Andrea Costa.

Figure 1 - a. view of the hills and forests of Serra dos Órgãos region at Teresópolis; b-c. Nidularium antoineanum; d. N. scheremetiewii; e. N. longiflorum; f. Canistropsis microps; g. N. fulgens; h. N. ferdinando-coburgii; i. N. innocentii. Photos: Igor Kessous and Andrea Costa. 
primário ou consideravelmente regeneradas, as quais apresentam rica variedade de palmeiras, epífitas e grandes árvores. Estes dados poderão ser ampliados, a partir de novos que incluam áreas recentemente incorporadas ao parque (Cronenberger \& Viveirosde-Castro 2007).

Sua altitude varia desde 200 m.s.m. em Santo Aleixo, onde predomina a Floresta Pluvial Baixo Montana com espécies de grande porte, até os campos de altitude, que atingem 2.263 m.s.m. na Pedra do Sino, com vegetação campestre ou de porte arbustivo se desenvolvendo sobre afloramentos rochosos.

\section{Levantamento e coleta}

O levantamento bibliográfico foi realizado nas principais monografias da família (e.g., Mez 1892-4, 1896, 1934-5; Smith \& Downs 1979) e protólogos das espécies do gênero. As publicações de novas espécies foram levantadas em Luther \& Sieff (1994, 1997), Luther (2001), Luther \& Rabinowitz (2010), e Leme $(1998,2000)$. Posteriormente foi realizado o levantamento nos principais herbários do estado do Rio de Janeiro (R, RB e HB, siglas em Thiers continuamente atualizado). O trabalho de campo consistiu em expedições de coleta de material botânico em trilhas existentes no parque, além de caminhadas aleatórias em matas em áreas remotas do parque. Os espécimes epífitos acima de $2 \mathrm{~m}$ de altura foram coletados com auxílio de tesoura de poda alta sempre que possível. Foram anotadas as características morfológicas que se perdem com a herborização, como cores, posições e posturas, assim como as localizações e altitude.

\section{Estudo taxonômico}

Para o estudo taxonômico, os espécimes coletados foram identificados com auxílio de literatura especializada, com auxílio de microscópio estereoscópico do laboratório de taxonomia do Museu Nacional. Análises das coleções de herbário também foram realizadas. As descrições das espécies foram feitas com base na variação morfológica observada em todos os exemplares provenientes da região, acrescentando-se as observações presentes nas etiquetas das exsicatas. A terminologia morfológica utilizada seguiu Gonçalves \& Lorenzi (2007), Rardford (1986), e Scharf \& Gouda (2008). Foram analisados caracteres como hábito, folha, inflorescência, brácteas e flores. Em caso de materiais incompletos, as descrições foram complementadas com as informações fornecidas por Leme (1998, 2000). Os dados de distribuição geográfica e habitat foram retirados de Martinelli et al. $(2008,2009)$ e da Lista de espécies da Flora do Brasil (BFG 2015). A classificação das formações vegetais seguiu Veloso et al. (1991) e de altitudes seguiu Rizzini (1997).

\section{Resultados e Discussão}

Foram inventariadas oito espécies, sendo uma de Canistropsis e sete de Nidularium. Nenhuma espécie consta no Livro Vermelho da Flora do Brasil.

\section{Chave para identificação dos gêneros Canistropsis e Nidularium no PARNASO}

1. Brácteas florais ca. $15 \mathrm{~mm}$, flores até $30 \mathrm{~mm}$ de comprimento; pétalas estreitamente lanceoladoespatuladas, ca. $25 \mathrm{~mm}$, concrescidas por $13 \mathrm{~mm}$, brancas com mancha verde na base, não cuculadas, lacíneas recurvado-patentes na antese. Canistropsis

1'. Brácteas florais ca. $24 \mathrm{~mm}$, flores maiores que $42 \mathrm{~mm}$ de comprimento com pétalas espatuladas, 31-55 $\mathrm{mm}$, concrescidas por $23-48 \mathrm{~mm}$, brancas com ápice azul ou roxo, liláses com ápice vermelho ou verdes com ápice branco, arredondado, cuculadas, formando uma corola clavada, eretas na antese

Nidularium

\section{Canistropsis (Mez) Leme}

Gênero com 11 espécies (Gouda et al. continuamente atualizado), endêmico da Mata Atlântica (Martinelli 2008; BFG 2015), ocorrendo apenas na Floresta Ombrófila Densa e Restinga (BFG 2015), entre o sul da Bahia e Santa Catarina (Martinelli et al. 2008; BFG 2015). No PARNASO possui apenas uma espécie, sendo Canistropsis microps f. pallida (L.B.Sm.) Leme com o materialtipo referido para a área. Ocorre em regiões mais baixas como nos arredores do Rio Soberbo e Barreira (400-500 m) em Guapimirim, e na Serra da Estrela (200-800 m).

1. Canisropsis microps (E. Morren ex Mez) Leme, Canistropsis - Bromélias da Mata Atlântica. 35. 1998.

Fig. 1f

Planta saxícola, epífita ou rupícola, estolonífera, $10-15 \mathrm{~cm}$ de altura. Folhas ca. de 10 , formando pequena roseta infundibuliforme; 
bainha elíptica, ovada ou obovada, 5-10 × 3-6 $\mathrm{cm}$, verde ou verde-alvacenta, indumento lepidoto denso em ambas as faces; lâmina lanceolada ou lanceolado-espatulada, 13,5-34 × 2-3,2 cm, verde ou verde-discolor, indumento lepidoto esparso em ambas as faces, ápice agudo ou obtuso, com projeção apiculada, margem serrilhada, acúleos 0,5-1 mm, espaçados por 3-7 mm. Inflorescência 2,5-5 cm de largura, obcônico-capitada, com flores congestas; pedúnculo com indumento esparso, alvacento, $5,2-8,8 \mathrm{~cm}$; brácteas do pedúnculo ca. $6 \mathrm{~cm}$, ovadas, ápice agudo ou acuminado, com pequena projeção apiculada, margem serrilhada, verde-alvacentas, indumento lepidoto em ambas as faces. Fascículos ca. 5, brácteas primárias $3-6 \mathrm{~cm}$, ovadas, ápice agudo, projeção apiculada, margem serrilhada, verdes ou vermelho-arroxeadas, indumento lepidoto esparso em ambas as faces. Brácteas florais ovadas, ca. $15 \mathrm{~mm}$, ápice agudo, sem projeção, margem inteira a remotamente espinulosa no ápice, liláses ou hialino-purpúreas, indumento lepidoto esparso. Flores 6-15, 25-30 $\mathrm{mm}$; sépalas ovadas, $10-15 \mathrm{~mm}$, concrescidas por até $3 \mathrm{~mm}$, ápice agudo, margem inteira, sem carena, ligeiramente assimétricas, liláses ou verde-alvacentas, indumento lanuginoso em direção ao ápice; pétalas estreitamente lanceoladoespatuladas, ca. $25 \mathrm{~mm}$, concrescidas por 13 $\mathrm{mm}$, brancas, com mancha verde na base, ápice arredondado, glabras, não cuculadas, lacíneas recurvado-patentes na antese; estames ca. $18 \mathrm{~mm}$; gineceu com ovário ínfero elipsoide e estigma espiral-conduplicado. Frutos ovoides brancos com ápice azulado com metade basal do cálice persistente azul e metade superior branca.

Material selecionado: Serra dos Órgãos, Fazenda Barreiras, 20.XI.1932, fl., Brade 12084 (R). Guapimirim: Parque Nacional da Serra dos Órgãos, Trilha sobre a ponte do Rio Soberbo na BR-116, 3.IV.2013, fr., Kessous 52 (R). Petrópolis: Serra da Estrela, 9.X.1967, fl., Pereira 10631 (HB); Estrada do Imperador, 4.XI.1967, fl., Braga 9 (HB); Serra da Estrela, leito da antiga estrada de ferro, margem direita do Rio Una, 500 m.s.m., 30.III.1977, fr., Martinelli 1583 (RB).

Canistropsis microps possui três formas as quais são distintas entre si pela coloração das brácteas primárias (entre totalmente verdes a totalmente vermelhas) (Leme 1998). É endêmica dos estados do Rio de Janeiro e São Paulo, e habita a Floresta Ombrófila Densa e a Restinga. No PARNASO, ocorre nas menores altitudes, na Floresta Pluvial Baixo Montana de Guapimirim e Petrópolis. Esta espécie possuia para a área do parque apenas coletas antigas realizadas há mais de 35 anos, no entanto foi encontrada recentemente em estádio de fruto nas matas do Rio Soberbo, na Sede Guapimirim. Esta região abrigava no passado a Fazenda da Barreira, localidade da coleta do material tipo de Nidularium microps $\mathrm{f}$. pallidum L.B.Sm. (Brade 12084, R; basiônimo de C. microps f. pallida). A espécie ocorre em populações umbrófilas com muitos indivíduos epífitos, saxícolas e rupícolas nas matas de encosta até 600 m.s.m. No entanto, não foi citada no Plano de Manejo do parque. Optou-se por não utilizar a classificação infraespecífica.

\section{Nidularium Lem.}

O gênero é endêmico do Brasil, com cerca de 45 espécies (Gouda et al. continuamente atualizado) presente no domínio da Mata Atlântica, ocorrendo no sul da Bahia e em todos os estados das regiões Sudeste e Sul do Brasil (Martinelli et al. 2008; BFG 2015). Ocorre em Campo de Altitude, Campo Rupestre, Floresta Estacional Semidecidual, Floresta Ombrófila Densa e Mista, Manguezal e Restinga (BFG 2015). No PARNASO é o quarto gênero mais diverso de Bromeliaceae, com sete espécies. Possui populações desde as regiões mais baixas (200-800 m), em Santo Aleixo, Serra da Estrela e em Guapimirim, até regiões mais altas (1.000-1.500 m) em Teresópolis e no Vale do Jacob, em Petrópolis. A espécie com maior número de coletas na região foi $N$. antoineanum.

\section{Chave de identificação das espécies de Nidularium no PARNASO}

1. Lâminas foliares com acúleos maiores que $1,5 \mathrm{~mm}$ de comprimento 5. Nidularium fulgens

1'. Lâminas foliares com acúleos até $1,5 \mathrm{~mm}$ de comprimento.

2. Plantas estoloníferas.

3. Lâminas verdes discolores, brácteas primárias com 6,5-11 cm, verdes, vermelhas em direção ao ápice, brácteas florais triangulares com ápice arredondado .... 7. Nidularium longiflorum

3'. Lâminas com face adaxial verde com máculas vermelhas e face adaxial purpúrea, brácteas primárias 5-6,5 cm, purpúreas, brácteas florais ovadas com ápice agudo. 
2'. Plantas se propagando por meio de brotos.

4. Inflorescência com pedúnculo $15-30 \mathrm{~cm}$

3. Nidularium antoineanum

4'. Inflorescências com pedúnculo até $12,5 \mathrm{~cm}$ de comprimento.

5. Acúleos até $0,3 \mathrm{~mm}$ de comprimento; sépalas oblanceoladas, ca. $12 \mathrm{~mm}$ de comprimento, concrescidas por $8 \mathrm{~mm}$ 4. Nidularium ferdinando-coburgii

5'. Acúleos maiores que $0,3 \mathrm{~mm}$ de comprimento; sépalas elípticas e obovadas, de 17-25 $\mathrm{mm}$, concrescidas por até $5 \mathrm{~mm}$.

6. Lâminas com face abaxial vinácea; brácteas florais ca. $36 \mathrm{~mm}$ de comprimento; flores ca. $63 \mathrm{~mm}$ de comprimento; sépalas com ápice arredondado

6. Nidularium innocentii var. innocentii

6'. Lâminas com face abaxial verde, brácteas florais ca. $25 \mathrm{~mm}$ de comprimento; flores ca. $50 \mathrm{~mm}$ de comprimento; sépalas com ápice agudo. 8. Nidularium scheremetiewii

2. Nidularium altimontanum Leme, Bradea 5 (16): 167, est. 1. 1989.

Planta terrestre, estolonífera, ca. 14 $\mathrm{cm}$ de altura. Folhas ca. 9, formando roseta infundibuliforme; bainha ovada, $8-11 \times 4,8-5,8$ $\mathrm{cm}$, verde-alvacenta em direção à base e vinosa em direção ao ápice, indumento lepidoto denso em ambas as faces; lâmina linear, 8,5-29,5 × 1,5-2 $\mathrm{cm}$, verde maculada de vermelho na face adaxial e com face abaxial purpúrea, indumento lepidoto esparso em ambas as faces, ápice agudo, com projeção apiculada, margem serrilhada, acúleos ca. $0,6 \mathrm{~mm}$, espaçados por 4-10 $\mathrm{mm}$. Inflorescência ca. 8,5 cm de largura, subcapitado-obcônica, com flores congestas; pedúnculo glabro, alvacento, ca. $6 \mathrm{~cm}$; brácteas do pedúnculo ca. $5 \mathrm{~cm}$, com pequena projeção apiculada, margem serrilhada, purpúreo-vinosas, indumento lepidoto em ambas as faces. Fascículos ca. 8, brácteas primárias 5-6,5 cm, ovadas a triangulares, ápice agudo, projeção apiculada, margem serrilhada, purpúreas, indumento lepidoto denso em direção à base. Brácteas florais ovadas, ca. $25 \mathrm{~mm}$, ápice agudo, com pequena projeção apiculada, margem inteira a densamente espinulosa no ápice, alvacentas, róseas e vermelho-escuras em direção ao ápice, indumento lepidoto esparso. Flores 10-15, ca. 45 $\mathrm{mm}$; sépalas obovadas, ca. $20 \mathrm{~mm}$, concrescidas por $5 \mathrm{~mm}$, ápice arredondado a agudo, margem inteira, levemente carenadas, simétricas, vermelhas, indumento lepidoto esparso; pétalas espatuladas, ca. $35 \mathrm{~mm}$, concrescidas por $23 \mathrm{~mm}$, liláses com ápice vermelho, ápice arredondado, glabras, cuculadas; estames ca. $31 \mathrm{~mm}$, filetes adnatos às pétalas por $23 \mathrm{~mm}$; gineceu com ovário ínfero ovoide e estigma espiral-conduplicado. Frutos brancos em direção à base e vermelhos no ápice, cálice persistente vermelho.
Material selecionado: Petrópolis: Serra da Estrela, 17.II.1968, fl., Pereira 10687 (HB).

Espécie endêmica do Rio de Janeiro, habita a Floresta Ombrófila Densa. No parque, esta espécie ocorre apenas na Floresta Pluvial Baixo Montana em Petrópolis na Serra da Estrela. A planta possui endemismo na região montana de Petrópolis, no entanto não foi recoletada no âmbito do projeto. Seu tipo não se encontra no Herbarium Bradeanum como citado originalmente em sua descrição. Não está citada na lista de espécies do Plano de Manejo do parque.

3. Nidularium antoineanum Wawra, Oesterreichische Botanische Zeitschrift 30: 113. 1880.

Fig. $1 b-c$

Planta epífita, terrestre ou saxícola, propagando-se por meio de brotos axilares, 20-40 $\mathrm{cm}$ de altura. Folhas 12-15, formando roseta infundibuliforme; bainha elíptica a oblonga, $7-15,5 \times 3-7 \mathrm{~cm}$, verde-alvacenta, indumento lepidoto denso em ambas as faces; lâmina elíptica a oblanceolada, 9-54 × 1-3 cm, verde, levemente discolor, indumento lepidoto esparso em ambas as faces, ápice obtuso a agudo, com projeção apiculada, margem serrilhada, acúleos ca. 0,5-1 $\mathrm{mm}$, espaçados por $2-10 \mathrm{~mm}$. Inflorescência 3,5-10 cm de largura, subcapitado-rosulada, com flores congestas; pedúnculo glabro, alvacento, 15-30 $\mathrm{cm}$; brácteas do pedúnculo $7-17 \mathrm{~cm}$, oblanceoladas a triangulares, ápice obtuso, com pequena projeção apiculada, margem serrilhada, verde-alvacentas, indumento lepidoto em ambas as faces, denso em direção à base. Fascículos ca. 8, brácteas primárias 5-9 $\mathrm{cm}$, ovadas a triangulares, ápice agudo, projeção apiculada, margem serrilhada, vermelhas, indumento 
lepidoto esparso em ambas as faces. Brácteas florais elípticas, ca. $24 \mathrm{~mm}$, ápice arredondado com pequena projeção apiculada, margem inteira, alvacenta, indumento lepidoto esparso. Flores 10-15, ca. $42 \mathrm{~mm}$; sépalas oblanceoladas, ca. $14 \mathrm{~mm}$, concrescidas por $4 \mathrm{~mm}$, ápice agudo, margem inteira, levemente carenadas, simétricas, brancas com ápice róseo, glabras; pétalas espatuladas, ca. $32 \mathrm{~mm}$, concrescidas por 25 $\mathrm{mm}$, brancas com ápice roxo, ápice arredondado, glabras, cuculadas; estames ca. $33 \mathrm{~mm}$, filetes adnatos às pétalas por $25 \mathrm{~mm}$; gineceu com ovário ínfero obovoide e estigma espiral-conduplicado. Frutos brancos com cálice persistente verde.

Material selecionado: Soberbo, Estrada TeresópolisBahia, 15.VI.1968, fl., Sucre 3217 (RB); Petrópolis: Vale do Jacob, Serra dos Órgãos, estado do Rio, 1500 m.s.m., III ou IV.1952, Vidal II-1469 (R); Serra da Estrela, 19.III.1968, fl., Pereira 10658 (HB); Serra dos Órgãos, estrada Itaipava-Teresópolis, 21.IV.1968, fl., Braga 3 (RB); Estrada Petrópolis-Teresópolis, 8.IV.1969, fl., Braga 35 (RB); Correias, caminho para o Pico do Açú, 21.VI.1986, fl., Leme 925 (HB, RB); Parque Nacional da Serra dos Órgãos, matas ao redor da cachoeira do Vale do Cuiabá, 1.100 m, 8.IV.1999, fl., Silva 173 (R); Vale do Cuiabá, Parque Nacional da Serra dos Órgãos, IV.2001, fl., Moura 331 (R); Parque Nacional da Serra dos Órgãos, Vale do Rio Jacó, 22²6'29”S, 432'609”'W, 1.300-1.500 m.s.m., 7.IV.2011, fl., Costa 913 (R); Parque Nacional da Serra dos Órgãos, sede Petrópolis, Vale do Rio Bonfim, trilha para o Açu, Circuito das Bromélias, entre 1.018 e $1.172 \mathrm{~m}$ de altitude, 1.VI.2011, fr., Costa 927 (R); Parnaso, Trilha da Pedra do Inferno 23K 0693790 UTM 7507226, 1593 m.s.m., 10.III.2012, fl., Gonçalves 63 (R); Teresópolis, próximo ao abrigo 4, próximo a Pedra do Sino, no Parque Nacional da Serra dos Órgãos, 1950 m.s.m., VI.1952, Vidal II-3285 (R); Parque Nacional da Serra dos Órgãos, caminho para Pedra do Sino, 1.450 m.s.m., 27.IV.1977, bot., Martinelli 1717 (RB); Parque Nacional da Serra dos Órgãos, caminho para a Pedra do Sino, 1250 m.s.m., 21.X.1977, fr., Martinelli 3319 (RB); Parque Nacional da Serra dos Órgãos, entre o abrigo 2 e a base do Nariz do Frade, 24.V.1987, f1., Fontoura 147 (HB, RB); P.N. Serra dos Órgãos, caminho para Pedra do Sino, 800-1.000 m, 30.IV.1990, fl., Leme 1572 (HB); PARNA Serra dos Órgãos, Abrigo Paquequer, 21.II.2009, fl., Moura 939 (R); Parque Nacional da Serra dos Órgãos, trilha para a Pedra do Sino, arredores do abrigo 1, 6.V.2009, fl., Costa 865 (R); Parque Nacional da Serra dos Órgãos, trilha para a Pedra do Sino., 23.VIII.2010, fl., Gomesda-Silva 72 (R); Parnaso, Trilha para a Pedra do Sino, 11.V.2012, fl., Kessous 3 (R); Parnaso, início da Trilha para a Pedra do Sino, ca. 1.200 m, 30.VI.2014, fl., Kessous 117 (R).
A espécie ocorre em Minas Gerais, Rio de Janeiro e São Paulo, habita a Floresta Ombrófila Densa. No parque, ocorre na Floresta Pluvial Montana em Petrópolis e Teresópolis. É a espécie do gênero com maior número de coletas no parque principalmente pela sua exuberância e fácil acesso. Ocorre em populações umbrófilas com muitos indivíduos em sub-bosques das matas de encosta até ca. 1.400 m.s.m. Descrita por Wawra a partir de uma coleta realizada em Teresópolis que no entanto foi perdida. Consta da lista de espécies do Plano de Manejo do parque.

4. Nidularium ferdinando-coburgii Wawra, Oesterreichische Botanische Zeitschrift 30: 112. 1880.

Fig. $1 \mathrm{~h}$

Planta epífita, propagando-se por meio de brotos axilares, ca. $16 \mathrm{~cm}$ de altura. Folhas ca. 10 , formando roseta infundibuliforme; bainha elíptica a oblonga, $6,5-10,5 \times 3,5-4,5 \mathrm{~cm}$, verdealvacenta, indumento lepidoto denso em ambas as faces; lâmina linear a estreito-elíptica, 8,5-48,5 $\times 1-2 \mathrm{~cm}$, verde, levemente discolor, indumento lepidoto esparso em ambas as faces, ápice obtuso a agudo, com projeção apiculada, margem serrilhada, acúleos ca. $0,3 \mathrm{~mm}$, espaçados por 4-5 mm. Inflorescência 8,5-17 cm de largura, subcapitado-rosulada, com flores congestas; pedúnculo glabro, alvacento, ca. $11 \mathrm{~cm}$; brácteas do pedúnculo ca. 7,5 cm, elípticas, ápice obtuso, com pequena projeção apiculada, margem serrilhada, verde-alvacentas, indumento lepidoto em ambas as faces, denso em direção à base. Fascículos ca. 9, brácteas primárias ca. $11 \mathrm{~cm}$, triangulares, ápice agudo, projeção apiculada, margem serrilhada, vermelhas com ápice verde, indumento lepidoto denso em direção à base. Brácteas florais oblanceoladas, ca. $26 \mathrm{~mm}$, ápice obtuso, sem projeção, margem inteira, alvacentas, glabras. Flores ca. 15, ca. $46 \mathrm{~mm}$; sépalas oblanceoladas, ca. $12 \mathrm{~mm}$, concrescidas por $8 \mathrm{~mm}$, ápice agudo, levemente apiculadas, margem inteira, levemente carenadas, simétricas, verde-alvacentas, glabras; pétalas espatuladas, ca. $31 \mathrm{~mm}$, concrescidas por $23 \mathrm{~mm}$, brancas com ápice azul, ápice arredondado, glabras, cuculadas; estames ca. $27 \mathrm{~mm}$, filetes adnatos às pétalas por $19 \mathrm{~mm}$; gineceu com ovário ínfero oblongoelíptico e estigma espiral-conduplicado. Frutos vermelho-escuros em direção ao ápice com cálice persistente vermelho.

Material selecionado: Guapimirim, Parque Nacional da Serra dos Órgãos Parnaso, Trilha para o Poço Verde, 
8.IV.2009, fl., Costa 853 (R); Parnaso, Vale do Rio Soberbo, trilha ao lado da ponte sobre o rio entre $\mathrm{Km}$

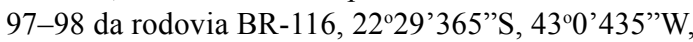
altitude entre 450-550 m.s.m. 22.VIII.2009, fr., Costa 875 (R); Parnaso, Vale do Rio Soberbo, trilha ao lado da ponte sobre o rio entre Km 97-98 da rodovia BR$116,22^{\circ} 29^{\prime} 365^{\prime} \mathrm{S}, 43^{\circ} 0$ '435' $\mathrm{W}$, altitude entre 450-550 m.s.m. 22.VIII.2009, fr., Costa 876 (R); Parnaso, Vale do Rio Bananal, Condomínio, Monte Olivete, 2230'236"S, 431'184"W entre 450-550 m.s.m. 23.VIII.2009, fr., Costa 879 (R); Parque Nacional da Serra dos Órgãos-Parnaso, Trilha para o Poço Verde, 24.VIII.2010, fr., Gomes-da-Silva 76 (R); Parque Nacional da Serra dos Órgãos, Vale do Rio Soberbo, 22'29'401'S, 430'019'W, 490-660 m.s.m. 11.IV.2011, fl., Costa 918 (R); Parnaso, Trilha do Rio Soberbo, 23K 074469 / UTM 7511750 - 572 m, 5.VIII.2011, fl., Gonçalves 14 (R).

Espécie endêmica dos estados de Minas Gerais e Rio de Janeiro, habita a Floresta Ombrófila Densa. No parque, esta espécie ocorre na Floresta Pluvial Baixo Montana na região do Soberbo em Guapimirim. Planta bastante frequente nas regiões mais baixas do parque com coletas recentes. A espécie ocorre em populações umbrófilas com poucos indivíduos epífitos em sub-bosques das matas de encosta até ca. 700 m.s.m. Consta da lista de espécies do Plano de Manejo do parque.

5. Nidularium fulgens Lemaire, Jardin Fleuriste 4(Misc.): 60, t. 411. 1854.

Fig. $1 \mathrm{~g}$

Planta epífita, rizomatosa, ca. $16 \mathrm{~cm}$ de altura.

Folhas ca. 25, formando roseta infundibuliforme; bainha elíptica a oblonga, 8,5-15,5 ×4,5-8,5 cm, verde-alvacenta, indumento lepidoto denso em ambas as faces; lâmina triangular, oblanceolada e elíptica, $11-34 \times 1,5-5,5 \mathrm{~cm}$, verde, maculada de verde-claro, indumento lepidoto esparso em ambas as faces, ápice obtuso a agudo, com projeção apiculada, margem serrilhada, acúleos ca. $5 \mathrm{~mm}$, espaçados por 5-10 mm. Inflorescência 8-12 cm de largura, subcapitado-rosulada, com flores congestas; pedúnculo glabro, alvacento, ca. $7 \mathrm{~cm}$; brácteas do pedúnculo $7,5-15,5 \mathrm{~cm}$, elípticas e triangulares, ápice obtuso a agudo, com pequena projeção apiculada, margem serrilhada, verde-alvacentas, indumento lepidoto em ambas as faces, denso em direção à base. Fascículos ca. 9, brácteas primárias ca. 9,5 cm, triangulares, ápice agudo, projeção apiculada, margem serrilhada, róseo-avermelhadas, indumento lepidoto denso em direção à base. Brácteas florais lanceoladas, ca. $29 \mathrm{~mm}$, ápice agudo, sem projeção, margem inteira, alvacenta, indumento lepidoto esparso. Flores 15-20, com mais de $43 \mathrm{~mm}$; sépalas estreito-elípticas, ca. $19 \mathrm{~mm}$, concrescidas por $3 \mathrm{~mm}$, ápice agudo, margem inteira, levemente carenadas, simétricas, vermelhas ou róseas em direção ao ápice, indumento lepidoto esparso; pétalas espatuladas, ca. $50 \mathrm{~mm}$, concrescidas por $40 \mathrm{~mm}$, brancas com ápice azul, ápice arredondado, glabras, cuculadas; estames ca. 44 $\mathrm{mm}$, filetes adnatos às pétalas por $40 \mathrm{~mm}$; gineceu com ovário ínfero, obovoide e estigma espiralconduplicado. Frutos brancos com metade apical castanha, cálice persistente verde ou vermelho em direção ao ápice.

Material selecionado: Teresópolis, Serra dos Órgãos, Soberbo, 820 m.s.m., VII.1952, fr., Vidal II-3305 (R); Parque Nacional da Serra dos Órgãos, Trilha da Primavera, 6.II.2001, fl., Valente 27 (RB); Parnaso, sede, próximo a pousada, ca. 1.100 m, 30.IV.2014, fr., Kessous 118 (R); Parnaso, sede, próximo a pousada, ca. 1.100 m, 30.IV.2014, fr., Kessous 119 (R); Petrópolis, Serra da Estrela, 12.III.1967, fl., Pereira 10562 (HB); Serra da Estrela, meio da serra, 24.IV.1967, fl., Pereira 10579 (HB); 11.VII.1967, fr., Pereira 10603 (HB).

Espécie endêmica do Rio de Janeiro, habita a Floresta Ombrófila Densa. No parque ocorre na Floresta Pluvial Montana e Baixo Montana em Teresópolis e Petrópolis, dentro e fora dos seus limites, tendo ocorrência frequente até a Granja Comary. Planta bastante frequente e coletada por José Vidal em suas expedições pela Serra dos Órgãos da década de 1950. Facilmente distinguida das outras espécies do gênero por seus acúleos evidentes nas folhas e nas brácteas primárias. A espécie ocorre em populações semi-heliófilas com poucos indivíduos epífitos em sub-bosques das matas de encosta até 1.100 m.s.m. Consta na lista de espécies do Plano de Manejo do parque.

6. Nidularium innocentii var. innocenti Lemaire, L'Illustration Horticole 2(Misc.): 13. 1855.

Fig. $1 \mathrm{i}$

Planta terrestre, epífita ou rupícola, propagando-se por brotos axilares, 15-20 $\mathrm{cm}$ de altura. Folhas ca. 15, formando roseta infundibuliforme; bainha estreito-elíptica a elíptica, 8,5-13,5 ×3,5-7,5 cm, verde-alvacenta na face adaxial e branca na abaxial, roxa em direção à base, indumento lepidoto denso em ambas as faces; lâmina elíptica a oblanceolada, 6,5-47 × 2,3-5,5 $\mathrm{cm}$, verde-discolor na face adaxial e vinácea na abaxial, glabra, ápice obtuso a agudo, com projeção apiculada, margem serrilhada, acúleos 
ca. $1 \mathrm{~mm}$, espaçados por 3-7 mm. Inflorescência 6-13 cm de largura, capitado-rosulada, com flores congestas; pedúnculo glabro, alvacento, $8,5-10,5$ $\mathrm{cm}$; brácteas do pedúnculo $2-10 \mathrm{~cm}$, elípticas a ovadas, ápice agudo a obtuso, com pequena projeção apiculada, margem serrilhada, verdealvacentas, com indumento lepidoto em ambas as faces, denso em direção à base. Fascículos ca. 7 , brácteas primárias $6,5-11 \mathrm{~cm}$, ovadas a triangulares, ápice obtuso, projeção apiculada, margem serrilhada, vermelhas, esverdeadas em direção à base, indumento lepidoto denso em direção à base. Brácteas florais lanceoladas, ca. $36 \mathrm{~mm}$, ápice agudo, sem projeção, margem inteira, alvacenta, indumento lepidoto esparso. Flores ca. 15, ca. 63 mm; sépalas obovadas, ca. 25 $\mathrm{mm}$, concrescidas por $4 \mathrm{~mm}$, ápice arredondado, margem inteira, levemente carenadas, simétricas, verde-alvacentas, glabras; pétalas espatuladas, ca. $50 \mathrm{~mm}$, concrescidas por $35 \mathrm{~mm}$, brancas, ápice arredondado, glabras, cuculadas; estames ca. 43 $\mathrm{mm}$, filetes adnatos às pétalas por $36 \mathrm{~mm}$; gineceu com ovário ínfero obovoide e estigma espiralconduplicado. FRUTOS brancos a vermelhos com cálice persistente vermelho.

Material selecionado: Teresópolis, Serra dos Órgãos, perto de Teresópolis, XII.1896, Ule 4130 (R); no mato da Serra dos Órgãos, I.1897, Ule, (R 46331); Serra dos Órgãos, 1952, Vidal II-2518 (R); Parque Nacional da Serra dos Órgãos, II.1955, Vidal V-16 (R); P.N. Serra dos órgãos, 1000-1100 m.s.m., 22.II.1989, fl., Till 4116 (WU); Parnaso, Cascata dos Amores, próximo a entrada para trilha da Pedra da Bunda, 14.II.2011, fl., Gonçalves 44 (R); Parnaso, estrada para Barragem, próximo à pousada, 21.II.2011, fl., Uribbe 2 (R); Parnaso, Trilha do Dedinho de Nossa Senhora (pequena crista antes da via de escalada), 9.III.2012, fl., Gonçalves 54 (R); Parnaso, Trilha Suspensa, ca. $1.150 \mathrm{~m}$ de altitude, 20.V.2012, fr., Kessous 12 (R); Parnaso, Trilha Suspensa, ca. 1.150 m de altitude, 20.V.2012, fr., Kessous 13 (R).

Espécie endêmica do Domínio Atlântico no Rio de Janeiro, Bahia, São Paulo, Paraná, Santa Catarina e Rio Grande do Sul. Habita a Floresta Ombrófila Densa e a Restinga. No parque esta espécie ocorre na Floresta Pluvial Montana em Teresópolis. Possui uma grande população epífita semi-heliófila e umbrófila no vale do Rio Paquequer próximo a Trilha Suspensa a ca. 1.100 m.s.m.. Difere das demais variedades pelas folhas com coloração vinosa na face abaxial. Planta de distribuição muito ampla ao longo de todo Brasil variando sua coloração, no entanto dentro dos limites do parque, a espécie só ocorre em Teresópolis. Consta da lista de espécies do Plano de Manejo do parque.
7. Nidularium longiflorum Ule, Berichte der Deutschen Botanischen Gesellschaft 14: 408. 1896.

Fig. 1e

Planta terrestre ou epífita, estolonífera, ca. $17-20 \mathrm{~cm}$ de altura. Folhas ca. 15, formando roseta infundibuliforme; bainha elíptica a oblonga, $6,5-12 \times 3,5-6 \mathrm{~cm}$, verde-alvacenta, indumento lepidoto denso em ambas as faces; lâmina elíptica a oblanceolada, $13,5-30 \times 2-4 \mathrm{~cm}$, verde discolor, glabra, ápice obtuso a agudo, com projeção apiculada, margem serrilhada, acúleos ca. $1 \mathrm{~mm}$, espaçados por $5-10 \mathrm{~mm}$. Inflorescência $5,5-10 \mathrm{~cm}$ de largura, subumbelada, com flores congestas; pedúnculo glabro, alvacento, $7-10 \mathrm{~cm}$; brácteas do pedúnculo 4-9 cm elípticas, ápice obtuso, com pequena projeção apiculada, margem serrilhada, verde-alvacentas, indumento lepidoto em ambas as faces. Fascículos ca. 5, brácteas primárias 6,5$11 \mathrm{~cm}$, ovadas a triangulares, ápice agudo, projeção apiculada, margem serrilhada, verdes, vermelhas em direção ao ápice, indumento lepidoto, mais denso na face adaxial. Brácteas florais triangulares, ca. $24 \mathrm{~mm}$, ápice arredondado sem projeção, margem inteira, alvacenta, indumento lepidoto esparso. Flores ca. 12, ca. $66 \mathrm{~mm}$; sépalas espatuladas, ca. $24 \mathrm{~mm}$, concrescidas por $8 \mathrm{~mm}$, ápice arredondado, margem inteira, levemente carenadas, assimétricas, verde-alvacentas, indumento lepidoto esparso; pétalas espatuladas ca. $55 \mathrm{~mm}$, concrescidas por $48 \mathrm{~mm}$, verdes com ápice branco, ápice arredondado, glabras, cuculadas; estames ca. $49 \mathrm{~mm}$, filetes adnatos às pétalas por $40 \mathrm{~mm}$; gineceu com ovário ínfero obovoide e estigma espiral-conduplicado. Frutos estreito-obovoides, brancos com cálice persistente verde ou vermelho em direção ao ápice.

Material selecionado: Teresópolis, Serra dos Órgãos, 1952, Vidal II-1904 (R); Parque Nacional da Serra dos Órgãos, entre a Barragem e o abrigo 2, 25.IV.1954, fl., Pabst 16950 (HB); Parque Nacional da Serra dos Órgãos, II.1955, Vidal V-17 (R); Parque Nacional da Serra dos Órgãos, caminho para a Pedra do Sino, 1.450 m.s.m., 27.IV.1977, bot., Martinelli 1724 (RB); Parque Nacional da Serra dos Órgãos, caminho para Pedra do Sino, 1300 m.s.m., 21.X.1977, bot., Martinelli 3316 (RB); Parque Nacional da Serra dos Órgãos, Barragem do Rio Beija-Flor, 900-1.000 m.s.m., 2.II.1983, fl., Martinelli 9077 (RB); Parque Nacional da Serra dos Órgãos, Trilha Mozart, 23.VIII..2003, fr., Forzza 2416 (RB); Parnaso, Trilha do Cartão Postal, 21.II.2011, fl., Uribbe 3 (R); Parnaso, Trilha da Primavera, ca. 1.037 m de altitude, $22^{\circ} 26$ '58.9'S, 42 59'19.9'SO, 20.V.2012, fr., Kessous 10 (R); Parnaso, estrada, próximo a Trilha da Primavera, ca. 1.050 m, 30.VI.2014, fr., Kessous 116 (R); Petrópolis, Vale do Jacob, na Serra dos Órgãos, III 
ou IV.1952, fr., Vidal II-1395 (R); Serra da EstrelaRocio, 28.I.1968, fl., Pereira 10676 (HB); Trilha do Cachambu Grande, 15.III.2011, fl., Uribbe 10 (R); Magé, Parque Nacional da Serra dos Órgãos, Vale do Rio Santo Aleixo, Andorinhas, Trilha Coruja-Italianos, 22.31'37'S, 43¹'59'W, 6.IV.2011, fr., Costa 903 (R); Parque Nacional da Serra dos Órgãos, Vale do Rio Santo Aleixo, Andorinhas, trilha Coruja-Italianos, 2231'37'S, 431'59'W, 6.IV.2011, fr., Costa 905 (R).

Espécie endêmica da região sudeste, habita a Floresta Ombrófila Densa e a Floresta Estacional Semidecidual. No parque esta espécie ocorre na Floresta Pluvial Montana e Baixo Montana em todos os municípios que delimitam o parque com exceção de Guapimirim. Espécie bastante frequente no parque ocorre em populações semiumbrófilas com indivíduos esparsos epífitos em sub-bosques das matas de encosta até ca. 1.000 m.s.m. Possui muitos problemas de identificação em coleções de herbário, principalmente por ocorrer em simpatria com $N$. antoineanum na Trilha para Pedra do Sino. Nidularium longiflorum difere de $N$. antoineanum principalmente pela cor verde com ápice avermelhado das brácteas primárias ( $v s$. inteiramente vermelhas) e das pétalas com ápice branco ( $v s$. ápice azul), no entanto após a herborização, alguns indivíduos são de difícil distinção. Esta espécie não foi citada no Plano de Manejo do parque.

8. Nidularium scheremetiewii Regel, Index Seminum [St. Petersburg] 1857: 28. 1858.

Fig. 1d

Planta epífita, propagando-se por brotos axilares, ca. $20 \mathrm{~cm}$ de altura. Folhas ca. 12, formando roseta infundibuliforme; bainha ovada, 4-10 × 3,5-5 cm, verde-alvacenta, indumento lepidoto denso em ambas as faces; lâmina estreito-elíptica, 7,8-25 × 1,8-2 cm, verde-discolor, indumento lepidoto esparso em ambas as faces, ápice agudo, com projeção apiculada, margem serrilhada, acúleos 0,8-1,5 $\mathrm{mm}$, espaçados por 4-14 mm. Inflorescência ca. $12 \mathrm{~cm}$ de largura, obcônica, com flores congestas; pedúnculo glabro, alvacento, ca. 12,5 $\mathrm{cm}$; brácteas do pedúnculo ca. $6 \mathrm{~cm}$, com pequena projeção apiculada, margem serrilhada, verdealvacentas, com indumento lepidoto em ambas as faces. Fascículos ca. 6, brácteas primárias ca. $12 \mathrm{~cm}$, ovadas a triangulares, ápice agudo, projeção apiculada, margem serrilhada, róseas a vermelhas na metade superior, indumento lepidoto denso em direção à base. Brácteas florais ovado-lanceoladas, ca. $25 \mathrm{~mm}$, ápice agudo, com pequena projeção apiculada, margem inteira, alvacenta, indumento lepidoto esparso. Flores ca. 15, ca. $50 \mathrm{~mm}$; sépalas elípticas a elíptico-obovadas, ca. $17 \mathrm{~mm}$, concrescidas por $5 \mathrm{~mm}$, ápice agudo, levemente apiculadas, margem inteira, levemente carenadas, simétricas, verdes, glabras; pétalas espatuladas, ca. $40 \mathrm{~mm}$, concrescidas por $30 \mathrm{~mm}$, brancas com ápice azul, ápice arredondado, glabras, cuculadas; estames ca. $35 \mathrm{~mm}$, filetes adnatos às pétalas por $28 \mathrm{~mm}$; gineceu com ovário ínfero obovoide e estigma espiral-conduplicado. Frutos brancos, cálice persistente verde.

Material selecionado: Petrópolis, Serra da Estrela, 31.XII.1967, fl., Pereira 10649 (HB); Teresópolis, Barreira, Serra dos Órgãos, 10.XII.1948, fr., Duarte 1593 (RB); P.N. Serra dos Órgãos, 400 m.s.m., 10.III.1991, fl., Leme 1701 (HB).

Espécie endêmica do Rio de Janeiro, habita a Floresta Ombrófila Densa. No parque esta espécie ocorre na Floresta Baixo Montana na Serra da Estrela em Petrópolis e em Guapimirim. Espécie menos frequente no parque, possui apenas coletas antigas, sendo a última há mais de 20 anos. A espécie ocorre em populações umbrófilas com muitos indivíduos epífitos em sub-bosques das matas de encosta até ca. 700 m.s.m. Consta da lista de espécies do Plano de Manejo do parque.

\section{Agradecimentos}

Os autores agradecem ao CNPq, as bolsas de estudos concedidos a I.M.K., a bolsa de Produtividade em pesquisa a A.F.C. (processo \# 307057/2011-9 e 304899/2014-3), e os recursos através do edital Protax (processos \# 562187/20103). À Concessionária Rio-Teresópolis S/A (CRT), os recursos para as expedições no campo. À equipe de Pesquisa do PARNASO, especialmente a Cecília C. Faria. Aos monitores Pheterson G. Oliveira e Ricardo L. Correia, o auxílio durante as coletas. À equipe do projeto Bromeliaceae organensis, em especial a Luís Fernando G. Silva. Ao Museu Nacional-UFRJ (Herbário e Setor de Transportes), o auxílio e infraestrutura. E aos curadores dos herbários, o acesso, o empréstimo e o envio de imagens de seus acervos.

\section{Referências}

Ayres, J.M.; Fonseca, G.A.B.; Rylands, A.B.; Queiroz, H.L.; Pinto, L.P.; Masterson, D. \& Cavalcanti, R.B. 2005. Os corredores ecológicos das florestas tropicais do Brasil. Sociedade Civil Maminaurá, Belém. 256p. 
Baker, J.G. 1889. Handbook of the Bromeliaceae. George Bell \& Sons., London. 243p.

BFG 2015. Growing knowledge: an overview of seed plant diversity in Brazil. Rodriguésia 66: 1085 1113.

Brown, G.K. \& Leme, E.M.C. 2000. Dados moleculares em Bromeliaceae. In: Leme, E.M.C. Nidularium: Bromélias da Mata Atlântica. Ed. Salamandra, Rio de Janeiro. Pp. 198-201.

Cronenberger, C. \& Viveiros-de-Castro, E. 2007. Ciência e conservação na Serra dos Órgãos. Instituto Chico Mendes de Conservação da Biodiversidade, Brasília. 296p.

Evans, T.M.; Jabaily; R.S.; Faria, A.P.G., Sousa, L.O. F., Wendt, T., \& Brown, G.K. 2015. Phylogenetic relationships in Bromeliaceae subfamily Bromelioideae based on Chloroplast DNA Sequence Data. Systematic Botany 40: 116-128.

Fundação SOS Mata Atlântica \& INPE (Instituto Nacional de Pesquisas Espaciais). 2001. Atlas dos remanescentes florestais da Mata Atlântica e ecossistemas associados no período de 19952000. Fundação SOS Mata Atlântica e INPE, São Paulo. 45p.

Galindo-Leal, C. \& Câmara, I.G. 2003. Atlantic forest hotspots status: an overview. In: Galindo-Leal, C. \& Câmara, I.G. (eds.). The atlantic forest of South America: biodiversity status, threats, and outlook. Center for Applied Biodiversity Science e Island Press, Washington, D.C. Pp. 3-11.

Givnish, T.; Millan, K.; Berry, P. \& Sytsma, K. 2007. Phylogeny adaptative radiation and historical biogeography of Bromeliaceae inferred from ndhF sequence data. In: Columbus, J.T.; Friar, E.A.; Hamilton, C.W.; Porter, J.M.; Prince, L.M. \& Simpson, M.G. (eds.). Monocots: comparative biology and evolution (3 vols.). Rancho Santa Ana Botanic Garden, Claremont. Pp. 3-26.

Givnish, T.J.; Barfuss, M.H.J.; Van Ee, B.; Riina, R.; Schulte, K.; Horres, R.; Gonsiska, P.A.; Jabaily, R.S.; Crayn, D.M.; Smith, J.A.C.; Winter, K.; Brown, G.K.; Evans, T.M.; Holst, B.K.; Luther, H.; Till, W.; Zizka, G.; Berry, P.E. \& Sytsma, K.J. 2011. Phylogeny, adaptive radiation, and historical biogeography in Bromeliaceae: insights from an eight-locus plastid phylogeny. American Journal of Botany 98: 872-895.

Gonçalves, E.G. \& Lorenzi, H. 2011. Morfologia Vegetal: organografia e dicionário ilustrado de morfologia das plantas vasculares. $2^{\text {a }}$ ed. Instituto Plantarum de Estudos da Flora, São Paulo. 512p.

Gouda, E.J.; Butcher, D. \& Gouda, K. [continuously updated]. 2012. Encyclopaedia of Bromeliads. Version 3.1 [and more or less continuously updated since 2012]. Available at $<$ http://encyclopedia. florapix.nl/>. Access on 26 April 2016.

Horres, R.; Schulte, K.; Weising, K. \& Zizka, G. 2007. Systematics of Bromelioideae (Bromeliaceae) -
Evidence from molecular and anatomical studies. Aliso 23: 27-43.

Leme, E.M.C. 1998. Bromélias da Mata Atlântica Canistropsis. Editora Salamandra, Rio de Janeiro. $143 \mathrm{p}$.

Leme, E.M.C. 2000. Bromélias da Mata Atlântica Nidularium. Editora Sextante, Rio de Janeiro. 263p.

Leme, E.M.C.; Till, W.; Brown, G.K.; Grant, J.R. \& Govaerts, R. 2008. Eduandrea, a new generic name for Andrea. Journal of the Bromeliad Society 58: 61-64.

Luther, H.E. 2001. De Rebus Bromeliacearum III. Selbyana 22: 34-67.

Luther, H.E. \& Sieff, E. 1994. De Rebus Bromeliacearum I. Selbyana 15: 9-93.

Luther, H.E. \& Sieff, E. 1997. De Rebus Bromeliacearum II. Selbyana 18: 103-140.

Luther, H.E. \& Rabinowitz, L. 2010. De Rebus Bromeliacearum IV. Selbyana 30: 147-189.

Martinelli, G.; Vieira, C.M.; Gonzalez, M.; Leitman, P.; Piratininga, A.; Costa, A.F. \& Forzza, R.C. 2008. Bromeliaceae da Mata Atlântica Brasileira: lista de espécies, distribuição e conservação. Rodriguésia 59: 209-258.

Martinelli, G.; Vieira, C.M.; Leitman, P.; Costa, A.F. \& Forzza, R.C. 2009. Bromeliaceae. In: Stehmann, J.R.; Forzza, R.C.; Salino, A.; Sobral, M.; Costa, D.P. \& Kamino, L.H.Y. (eds.). Plantas da Floresta Atlântica. Instituto de Pesquisas Jardim Botânico do Rio de Janeiro, Rio de Janeiro. Pp. 186-204.

Mez, C. 1892-4. Bromeliaceae. In: Martius, C.F.P. von; Eichler, A.W. \& Urban, I. Flora brasiliensis. München, Wien 3: 173-674.

Mez, C. 1896. Bromeliaceae. In: Candolle, A.L.P.P. de \& Candolle, A.C.P. de. Monographiae phanerogamarum. Vol. 9. G. Madison, Paris. Pp. 1-990.

Mez, C. 1934-5. Bromeliaceae. In: Engler, H.G.A. Das Pflanzenreich. Vol. 4.32. (Heft 100, 1-4). Wilhem Engelmen, Berlin. Pp. 1-667.

Myers, N.; Mittermeier, R.A.; Fonseca, C.G. \& Kent, J. 2000. Biodiversity hotspots for conservation priorities. Nature 403: 853-858.

Pereira, E. \& Leme, E.M.C. 1986. Contribuição ao estudo do gênero Nidularium (Bromeliaceae) - Parte 1 subgênero Canistropsis. Bradea 4: 219-254.

Radford, A.E. 1986. Fundamentals of plant systematics. Harper \& Row, Publishers, Inc., New York. 891p.

Ribeiro, M.C.; Metzger, J.P.; Martensen, A.C.; Ponzoni, F.J. \& Hirota, M.M. 2009. The Brazilian Atlantic Forest: how much is left, and how is the remaining forest distributed? Implications for conservation. Biological Conservation 142: 1141-1153.

Rizzini, C.T. 1979. Tratado de fitogeografia do Brasil aspectos sociológicos e florísticos. Vol. 2. Hucitec/ Ed. USP, São Paulo. 347p.

Sass, C. \& Specht, C.D. 2010. Phylogenetic estimation of the core Bromelioids with emphasis on the genus 
Aechmea (Bromeliaceae). Molecular Phylogenetics and Evolution 55: 559-571.

Scharf, U. \& Gouda, E.J. 2008. Bringing Bromeliaceae back to homeland botany. Journal of the Bromeliad Society 58: 123-129.

Schulte, K.; Barfuss, M.H. \& Zizka, G. 2009. Phylogeny of Bromelioideae (Bromeliaceae) inferred from nuclear and plastid DNA loci reveals the evolution of the tank habit within the subfamily. Molecular Phylogenetics and Evolution 51: 327-339.

Silvestro, D.; Zizka, G. \& Schulte, K. 2014. Disentangling the effects of key innovations on the diversification of Bromelioideae (Bromeliaceae). Evolution 68: 163-175.
Smith, L.B. 1955. The Bromeliaceae of Brazil. Smithsonian Miscellaneous Collections 126: 162172 .

Smith, L.B. \& Downs, R.J. 1979. Bromelioideae. Flora Neotropica Monograph 14: 1493-2142.

Thiers, B. [continuamente atualizado]. Index herbariorum: a global directory of public herbaria and associated staff. New York: Botanical Gardens Virtual Herbarium. Disponível em <http://sweetgum.nybg. org/ih/>. Acesso em 25 março 2015.

Veloso, H.P.; Rangel Filho, A.L.R. \& Lima, J.C.A. 1991. Classificação da vegetação brasileira adaptada a um sistema universal. Fundação IBGE, Rio de Janeiro. 116p. 